\title{
LEX MERCATORIA - HORIZONTE E FRONTEIRA DO COMÉRCIO INTERNACIONAL
}

\author{
Hermes Marcelo Huck \\ Professor Associado do Departamento de Direito Internacional \\ da Faculdade de Direito da Universidade de São Paulo.
}

\begin{abstract}
Resumo:
Não há comerciantes no espaço sideral. O comércio internacional tem suas bases nos territórios de Estados nacionais soberanos. Este o grande desafio e a maior dificuldade de se construir uma nova lex mercatoria: um direito, ou um conjunto de regras uniformes, para reger todo o comércio internacional. Esse direito sem fronteiras, nascido da prática constante do comércio, inspira-se no jus mercatorum do século $\mathrm{XI}$, fonte do direito comercial. O papel importante exercido pelo Estado no comércio internacional é o grande obstáculo à aceitação da nova lex mercatoria. A ilimitada adoção da lex mercatoria poderá conduzir à ditadura das frias regras de mercado, sem qualquer consideração com as regras políticas e jurídicas de cada Estado nacional. $O$ risco parece extremamente alto.
\end{abstract}

\begin{abstract}
:
There are not traders in the cosmic space. The international commerce is grounded on the national territories of every sovereign national State. This is the major challenge and difficulty to the building process of a new lex mercatoria: a new law, or a set of uniform rules, conceived to govern all the international commerce agreements. This law without borders has brought its inspiration from the jus mercatorum of the 11th. century, source of the modern Commercial Law. The important role of the State within the international commerce scene is the main obstacle to the acceptance of the new lex mercatoria. The unlimited adoption of the lex mercatoria may lead to the dictatorship of the always cold market rules, without any due regard to the political and juridical reasons of every national State. The risk involved is deemed to high.
\end{abstract}

1. Um antigo conceito revisitado.

Não há comerciantes sediados no espaço sideral. O comerciante está sempre estabelecido em determinado local, sobre determinado território, inexoravelmente vinculado à soberania de um determinado Estado. É a partir 
desse território nacional, sujeito às leis nele vigentes, que o comerciante abre sua atividade para o exterior, iniciando seu comércio internacional, mas sempre vinculado ao Estado de seu estabelecimento de origem. É admissível, entretanto, que tal comerciante, além dos vínculos que mantenha com o Estado de onde parte sua atividade, possa assumir com seus parceiros estrangeiros, estabelecidos em outros Estados soberanos, uma relação de natureza corporativa supranacional.

Tal relação supranacional, estabelecida no seio da grande sociedade dos comerciantes internacionais, busca uniformizar as regras jurídicas e contratuais de sua própria e específica atividade, harmonizando suas práticas de comércio, simplificando e agilizando o sistema mercantil transfronteiras. Inúmeros e notáveis são os esforços no sentido de uma padronização dos costumes comerciais internacionais. Ao lado das Convenções Internacionais buscando adotar regras uniformes para a prática do comércio internacional de mercadorias, ${ }^{1}$ diversas entidades privadas dedicam-se à uniformização dessas regras, tais como a UNIDROIT ou a Câmara de Comércio Internacional de Paris (CCI).

Vários são os autores que chegam a proclamar e defender o surgimento de um direito específico para essas relações comerciais internacionais, desvinculado dos direitos nacionais. O respeitado professor Schmittoff não hesita em noticiar a existência de um direito do comércio transnacional. ${ }^{2}$ Uma sociedade de comerciantes desvinculada do poder soberano de seus respectivos Estados, liberta de qualquer fronteira estatal, é o que chega a afirmar Berthold Goldman, o grande inovador nessa área do Direito Internacional. Tavares Guerreiro conclui que a comunidade internacional dos

1. As Convenções de Haia (1954) e de Viena (1980) definindo normas uniformes para a compra e venda internacional de mercadoria representam claros exemplos desses resultados uniformizadores.

2. Clive M. Schmittoff, Commercial law in a changing economic climate, Sweet \& Maxwell, London, 1981, p. 13. 
comerciantes configura realidade distinta da realidade estatal, igualmente capaz de editar suas próprias regras jurídicas. ${ }^{3}$

Essa sociedade autônoma de vendedores e compradores do comércio internacional, pela reiterada prática de atos e contratos, 'aliada a uma vontade específica para a criação de regras próprias a sua atividade, acabaria por gerar um direito distinto dos direitos nacionais, a que se denominaria de uma nova lex mercatoria. Os pregadores dessa lei autônoma e sem peias procuram dar-lhe a configuração de um autêntico sistema jurídico, distinguindo-o do tradicionalmente aceito costume comercial internacional. ${ }^{4}$

O movimento doutrinário para uma nova e moderna lex mercatoria aparece em 1964, sob a forma de artigo publicado por Goldman, lançando as bases para um direito positivo distinto e autônomo, regulando o comércio internacional, livre das barreiras e limitações impostas pelos direitos nacionais. ${ }^{5}$

A exemplo do ius mercatorum, nascido no século XI na esteira dos costumes comerciais, com jurisdição especial, baseado na autonomia corporativa e sem intervenção do Estado, pretende-se a concepção e vigência de uma nova lex mercatoria, concebida para este final de século XX.

A sociedade medieval estratificada vê nascer um ius mercatorum em decorrência de seu processo de urbanização. Não havia na Idade Média o conceito de classes, e quando, naquele momento histórico, se fala em "classe de

3. "O Estado, enquanto titular do poder normativo e fonte de regras jurisdicionais, configura uma realidade, mas essa comunidade de comerciantes ou agentes do comércio internacional configura outra realidade, não conflitante com a primeira, por se referir a interesses diferentes, mas igualmente podendo ser capaz de ser dotada de poder normativo distinto, e podendo se converter por igual forma, em fonte de regras jurídicas.", José Alexandre Tavares Guerreiro, Fundamentos da arbitragem comercial internacional, tese de doutorado, s.c.p., Sāo Paulo, 1989, p. 166.

4. Phillipe Kahn defende abertamente a tese de que os contratos-tipo, originários das associações internacionais de comerciantes, mais do que criar novos costumes, configuram a passagem do direito contratual ao direito positivo. V. Lex mercatoria et pratique des contrats internationaux: l'expérience française, in Le Contrat Économique International, Bruxelles-Paris, 1975 , p. 175.

5. Berthold Goldman, Les frontières du droit et lex mercatoria, in Archives de Philosofie du Droit, n. 9, 1964, p. 177. 
mercadores", não se vislumbra qualquer identidade com a noção políticoeconômica de classe que o marxismo difundiu a partir do século XIX. ${ }^{6}$

Por maior condescendência que se possa ter com a admissão de uma moderna lex mercatoria a suprimir dificuldades e barreiras no comércio internacional, há que se admitir que a postulação desse conceito se faz hoje numa sociedade internacionalizada (é verdade), onde as nações encontram-se divididas, muito mais do que por direitos nacionais distintos, mas por interesses comerciais conflitantes.

Um direito dos mercadores é alvo tão antigo quanto o próprio comércio. Traços de um sistema análogo podem ser encontrados já no ano 300 a.C. com a Lei do Mar de Rodes, adotada por gregos e romanos e, posteriormente, introduzida no restante da Europa. No curso do tempo, várias manifestações jurídicas no mesmo sentido são detectadas, tais como as regras de direito marítimo desenvolvidas pelo Imperador Basilio I, no século IX; as tábuas de Amalfi, editadas no século XI naquela República italiana; os rolos de Oleron, surgidos no século XII na Corte de Oleron, uma ilha atlântica da costa francesa; as leis de Wisby, que desde 1350 regulavam o comércio no mar Báltico; o Consulado do Mar, ainda no século XIV, uma coletânea de costumes do comércio marítimo, reunida pela Corte Consular de Barcelona e aceita em praticamente todos os centros comerciais marítimos da Europa.

Ao lado dessas regras, há o desenvolvimento de práticas comerciais difundidas e aceitas, cuja violação implicava a exclusão do comerciante do respectivo mercado.

Com a decadência das sociedades corporativas, ganha força o Estado nacional, notadamente após o século XIV. O direito comercial do Estado nacional assume o papel até então exercido pelo ius mercatorum dos comerciantes medievais.

A decadência das corporações (e consequentemente do ius mercatorum) e a prevalência do direito comercial são conseqüências do mesmo fenômeno da consolidação do Estado nacional moderno. Por coincidente que pareça, o mesmo Estado nacional, que decreta o fim do poder das corporações medievais, torna difícil a aceitação de uma lex mercatoria moderna. Estado e lex 
mercatoria são conceitos (e realidades jurídico-políticas) quase que excludentes, e certamente conflitantes.

Um corpo supranacional de regras jurídicas, desvinculado de qualquer estado soberano, a regular as relações comerciais internacionais, conflita frontalmente com o curso atual da história, ainda marcada pela tendência codificadora nascida nos séculos XVIII e XIX. Não se pode imaginar um direito desvinculado da história. A busca da interação social, econômica e política é uma resposta moderna e democrática para uma sociedade internacional transparente, sem castas dominantes, apta a livremente criar regras, independente de imposições ou coações. Um direito de classe, aplicável a todas as relações comerciais internacionais, sem o resguardo do Estado, ainda que com inegável vantagem utilitária, é, num primeiro momento, a negação daquela resposta democrática.

Schmittoff, defensor da nova lex mercatoria, reconhece que o caráter internacional desse corpo de regras há de ser conciliado com o conceito de soberania nacional dos Estados, sobre o qual se acha estruturada a vigente ordem mundial. ${ }^{7}$

\section{Lex mercatoria: conceito e origens.}

A despeito do imenso volume de trabalhos teóricos dedicados ao estudo da nova lex mercatoria publicados notadamente a partir da década de 1960, seja no sentido de defender a existência e divulgação desse corpo de regras comuns a todo o comércio internacional, seja para criticar tal proposta ou suas conseqüências, constata-se uma grande divergência entre os autores na busca de um conceito ou definição para tal conjunto ou sistema de regras.

A extensão, profundidade ou mesmo os fundamentos para uma definição variam, assim como varia a própria aplicabilidade do conceito. Goldman, o mais notável precursor da lex mercatoria, entende-a como um conjunto de princípios gerais e de regras costumeiras aplicadas espontaneamente ou elaboradas para o comércio internacional, sem referir a um específico sistema de direito nacional.

7. Ob. cit., nota 2, p. 21. 
Lando fala em regras de direito que são comuns a todos ou à maioria dos Estados envolvidos no comércio internacional ou para aqueles Estados envolvidos numa pendência comercial; não sendo tais regras identificáveis, eleger-se-ão aquelas que pareçam ser as mais apropriadas e equitativas.

Langen vê a lex mercatoria como as regras do jogo do comércio internacional, enquanto que Schmittoff a conceitua como princípios comuns do direito relativo às transações comerciais internacionais.

A verdadeira certidão de nascimento de uma nova lex mercatoria aparece em meados dos anos 60, por meio do trabalho de Berthold Goldman. Em 1964, seu artigo denominado Frontières du droit et lex mercatoria é publicado, passando a ser considerado como um marco no processo de evolução do conceito. $^{8}$

Goldman, neste conhecido artigo, procura demonstrar que as relações comerciais internacionais "parecem escapar ao império de um direito estatal, em direção a um direito uniforme integrado na legislação dos Estados que a ele tenham aderido" 9

$\mathrm{Na}$ elaboração de sua teoria, Goldman divide as operações do comércio internacional em três setores fundamentais. As operações de venda, onde ressalta a importância das associações de profissionais do comércio internacional, exemplificando com a London Corn Trade Association, as quais desenvolvem um notável trabalho com a elaboração de contratos-tipo, decisivos para a uniformização das regras do comércio internacional.

Ao lado das operações de venda, menciona as operações de crédito, dando particular atenção ao crédito documentário, cuja origem não é encontrada nas legislações nacionais, mas sim na prática e nos costumes internacionais. Finalmente menciona as operações de transporte, cuja natureza eminentemente internacional foi se traduzindo em regras uniformizadas.

Goldman, naquele momento, entendia a lex mercatoria dotada de âmbito e finalidade compatíveis com sua qualificação como um sistema jurídico.
8. Ob. cit., nota 5, p. 177-192.
9. Ibid., nota 5, p. 177. 
Por outro lado, perguntava-se se as regras que compõem o sistema podem ser consideradas como "normas" editadas por uma "autoridade" e dotadas de sanção. Neste ponto, lembrava a consagrada definição de Battifol, que considera a norma jurídica como uma prescrição de caráter geral, formulada com suficiente precisão, para que os interessados possam conhecê-la antes de agir. Para Goldman, a lex mercatoria, tal como então se apresentava, respondia quase integralmente aos requisitos prescritos por Battifol.

Da maior importância é, neste ponto, notar que, mesmo defendendo a existência e a necessidade de uma lex mercatoria para regular equilibradamente o comércio internacional, Goldman constatava a ocorrência de uma certa pressão no sistema, exercida pelos atores mais fortes do comércio internacional. Estes imporiam a aceitação da sistemática da lex mercatoria aos economicamente mais fracos, caso pretendessem participar de tal relacionamento. ${ }^{10}$

Procurando definir as bases de um sistema jurídico para a lex mercatoria, Goldman defendia originar-se a mesma de uma autoridade; não uma autoridade estatal, é verdade, mas uma autoridade profissional. São essas autoridades profissionais que ditam os contratos-tipo e que patrocinam a arbitragem, foro ideal para a implementação desse sistema jurídico de classe.

Para complementar sua descrição, Goldman argumentava que o sistema de direito do comércio internacional contaria inclusive com a coação, elemento essencial para a configuração plena de um sistema de direito. Essa coação seria exercida, num primeiro momento, através da pressão moral da classe dos comerciantes, por penalidades comerciais, pela publicidade, ou finalmente pelo próprio Estado.

10. "D'une part, l'éxperience concrète du commerce international parait bien établir qu'en fait "les petits sont obligés de suivre les règles établies par les gros" - en d'autres termes, que la plupart des entreprises devront bien si elles veulent participer au commerce international, adopter les contratstype elaborés par les organisations profissionelles ou les entreprises les plus puissantes de leur branche d'activité". Ob. cit., nota 5, p. 188. 
3. Lex mercatoria e direitos nacionais.

Neste ponto, merece particular atenção a constatação que Goldman faz, no citado artigo, da presença do Estado, dos direitos nacionais e dos tribunais estatais, quer como barreiras (ou fronteiras), quer como suplementos essenciais ao completo funcionamento do sistema da lex mercatoria.

Quando a coação do sistema mercatório falta, falha ou é insuficiente, não resta alternativa que não vinculá-lo ao direito estatal, de onde sempre quis fugir. Mesmo minimizando essa eventualidade, Goldman a reconhece amplamente.

Parte da afirmação de que, em alguns casos raros, a sentença arbitral fundamentada por normas próprias e específicas do comércio internacional, ou seja na lex mercatoria, não possa ser executada senão com a intervenção da força do Estado. Mesmo nessa hipótese, conclui o autor, o Estado nacional não há de negar exeqüibilidade à decisão, salvo por motivo de força maior. ${ }^{11}$

Goldman encerra seu famoso trabalho com a conclusão de que o sistema da lex mercatoria situa-se tanto formalmente como substancialmente dentro do domínio do direito, formando um conjunto adequado a regular as relações do comércio internacional.

4. O conflito da lex mercatoria com as soberanias nacionais.

A soberania do Estado é fonte e origem da lei. É fundamental que os Estados, através de seu poder jurisdicional ou legislativo, reconheçam a lex mercatoria, esse corpo consagrado de regras costumeiras a vigorar no comércio internacional, pois, caso contrário, não haverá forma de se impor a efetividade

11. "Il reste que dans quelques hypothèses statistiquement rares l'exécution de la sentence arbitrale appliquant les normes propres au commerce international ne pourra être obtenue que par l'intervention de la force publique. Mais nous ne pensons pas que cela laisse les normes elles-mêmes en dehors du droit; car précisément, cette ultime sanction leur est bien accordée, sauf si elles apparaissent, à travers la sentence, commes contraires à l'ordre publique du pays où l'exécution est requise. Elles ne restent par conséquent pas dépourvues de sanction et l'on peut seulement dire qu'elles doivent quelquefois, pour l'obtenir, faire appel à un ordre juridique étatique par rapport auquel elles se voulaient autonomes". Ob. cit., nota 5, p. 192. 
das mesmas dentro dos limites territoriais do Estado, e tal construção de normas tornar-se-á absolutamente ineficaz, simples jogo ou brinquedo nas mãos de uma poderosa classe internacional, esta sim sem fronteiras.

Essa vinculação de reconhecimento da lex mercatoria pelos tribunais estatais operar-se-á fundamentalmente através da aceitação e execução de laudos arbitrais prolatados com base na referida lex. Um tribunal nacional pode aceitar como válido, em determinadas (e raras) circunstâncias, um contrato fundado na lex mercatoria, tal como em casos julgados pela Suprema Corte da Áustria, a Corte de Cassação Francesa ou mesmo a London Court of Appeals, ${ }^{12}$ mas tal tribunal recusará sua aplicação se ela for contrária ou incompatível com o disposto na lei nacional interna.

A lex mercatoria é lei substantiva, não existindo como lei de conflito ou lei processual, mesmo para aqueles que a defendem intransigentemente. $\mathrm{Na}$ hipótese de sua aplicação por tribunais nacionais, ainda que parcialmente, ela se incorpora ao direito nacional, sujeita à interpretação dos legisladores e juízes nacionais. A aceitação da lei dos mercadores, na Idade Média, não esbarrava nas barreiras de judiciários nacionais, pois sua aplicação ocorria em tribunais próprios dos comerciantes, e destes tribunais jamais extravasava.

A ampla e irrestrita aceitação de uma lex mercatoria por parte de tribunais estatais caracterizaria um forte impacto nos conceitos vigentes, na medida que implicaria, como lembrou Stoecker, a concessão de parte da soberania do Estado em favor das mãos invisíveis de uma inconstante comunidade de comerciantes, que faz a lei de acordo com suas conveniências e necessidades. ${ }^{13}$

Tal qual a sentença estrangeira, fruto legítimo de uma soberania nacional, necessitando de reconhecimento de outra soberania nacional para vir a

12. Na década de 80, a Suprema Corte da Áustria reconheceu a viabilidade da lex mercatoria no caso Palback Ticaret Limited Sirkety (Turquia) v. Norslov S.A. (França), tendo o mesmo caso sido apresentado à Corte de Cassação da França que, igualmente, reconheceu a mesma lex como aplicável. A London Court of Appeals julgou no mesmo sentido, em 1987, o caso Deutsche Schachtbau und Tiefbohrgesellschafi m.b.h. (D.S.T.) v. Ras Al Khaimah National Oil Co. (Rakoil).

13. Christoph W.O. Stoecker, The lex mercatoria: to what extent does it exists?, in Journal of International Arbitration, vol. 7, n. 1, 1990, p. 108. 
produzir efeitos, um direito espontâneo, como a nova lex mercatoria, necessita do reconhecimento de um Estado soberano para ganhar eficácia. Caso contrário, poderá sempre prevalecer a ordem pública do Estado contra sua utilização e vigência. Será totalmente inútil o exercício de um tribunal arbitral, por exemplo, a decidir uma pendência do comércio internacional, com base em regras supranacionais, se o laudo exarado não puder ser executado em determinado território nacional, sob excusa de ferir a ordem pública.

Mesmo considerando a intervenção do poder judiciário nacional na arbitragem internacional como "patológica", tal intervenção não pode ser ignorada. Não são raras as situações em que, ainda no curso do procedimento arbitral, a interferência estatal é necessária para garantia da própria arbitragem. São inúmeras as possibilidades que podem ensejar essa intervenção: levantamento, apuração ou congelamento de contas bancárias, medidas cautelares em geral, alegação de parcialidade do árbitro, tudo sem mencionar a execução forçada do laudo prolatado, propriamente dita. ${ }^{14}$

Francisco Rezek, ex-Ministro do Supremo Tribunal Federal, ocupando o cargo de Ministro das Relações Exteriores do Brasil, em palestra proferida no Rio de Janeiro, em 1990, anotou com grande oportunidade que o enfraquecimento do conceito de soberania tem impacto negativo nos interesses de países de menor poder de barganha no cenário internacional. ${ }^{15}$ Tais países seriam profundamente afetados pela consagração de uma lei comercial criada e vigente acima dos direitos nacionais.

Contrariamente, Tavares Guerreiro bem resume o pensamento atual em favor da lex mercatoria, quando afirma que "a característica do comércio internacional hoje é a regulação de relaçōes econômicas por meio de um processo

14. Stoecker, ob. cit., nota 13 , p. 115 .

15. "A História ensina que, sempre que se enfraquecem conceitos como o de soberania, contrariam-se os interesses dos paises com menor poder no cenário internacional. A preocupaçâo brasileira é tanto mais procedente quando se recorda que, também no plano econômico e comercial, as extraordinárias mudanças no mundo não atingiram uniformemente a comunidade das nações $e$ seus benefícios de maneira alguma se deverão estender automaticamente a todos"., Francisco Rezek, palestra proferida na Escola Superior de Guerra no Rio de Janeiro, O Estado de S.Paulo, 29 de julho de 1990. 
normativo desencadeado na própria classe dos comerciantes ou agentes do comércio internacional" 16

5. O papel do Estado no comércio internacional.

A argumentação em favor de uma lex mercatoria, totalmente livre e desvinculada de peias com o Estado, não dimensiona adequadamente o papel que este continua a exercer no comércio internacional moderno. A despeito das manifestações desestatizantes que ocorrem em todos os níveis e quadrantes, em nenhum momento se pode ignorar o papel multifacetado que o Estado desempenha no comércio internacional, seja como poder jurisdicional, limitando e regulando o comércio que por suas fronteiras flui, seja através de práticas e políticas tributárias, normas alfandegárias etc.

Mesmo o mais liberal dos Estados intervém no comércio internacional, como sujeito de direito internacional público, pela elaboração de acordos e tratados internacionais, facilitando (ou às vezes dificultando) as relações comerciais entre as nações.

O Estado também age intensamente no cenário do comércio mundial de forma direta, em contratos e atividades que originalmente seriam concebidas apenas entre particulares. ${ }^{17}$

Ademais, o contrato internacional comercial de que o Estado participa, conhecido como Contrato com o Estado, ou o State Contract de que falam os autores anglo-americanos, reunindo o Estado e o contratante particular, tem grande relevância para a aplicação da lex mercatoria, pois vários teóricos, procurando fugir do direito nacional do Estado contratante a reger um contrato em que o próprio Estado é parte, buscam no direito transnacional solução para esta dificuldade.

É, portanto, múltipla a atividade do Estado no comércio internacional; ignorá-la, ou ainda desprezar a soberania como fator determinante das barreiras de ordem pública, a impedir que decisões, acordos ou mesmo

16. Ob. cit., nota 3, p. 207.

17. v. Hermes Marcelo Huck, Contratos com o Estado: aspectos de direito internacional, Sāo Paulo, Aquarela, 1989. 
contratos internacionais sejam reconhecidos em território nacional, é adotar uma utópica posição, pretendendo que o comércio transfronteiras seja o reino exclusivo dos international merchants, cenário inaceitável para a formulação de um direito científico e democrático, apto para uma sociedade internacional em acelerada e quase incontrolável transformação.

A dificuldade de utilização da lex mercatoria mesmo em contratos com o Estado é reconhecida por Delaume em criterioso trabalho sobre a aplicação da lei a tais contratos. O elaborador do contrato é advertido para que esteja atento na adoção da lex mercatoria como aplicável à relação contratual, pois ela continua estruturada sobre um direito nacional, ainda que não o do Estado contratante. Delaume ressalta que a indefinição dos limites da lex mercatoria pode conduzir a uma dificuldade de interpretação do contrato, requerendo essa tarefa interpretativa muito mais tempo do que seria lícito esperar-se, caso o contrato fosse governado por uma lei nacional facilmente acessível.

Finalmente, Delaume repele a crítica de que vários direitos nacionais, notadamente dos países menos desenvolvidos, não teriam instrumentação técnica necessária para regular contratos tão sofisticados. Afirma o autor que "hoje, a moderna legislação dos países do terceiro mundo é perfeitamente capaz de prover a maioria dos contratos com o Estado com uma estrutura legal sofisticada" 18

\section{Lex mercatoria e costume comercial internacional.}

Argumentos constantemente utilizados em defesa da aceitação da lex mercatoria recorrem a decisões jurisprudenciais nacionais ou acordos internacionais que teriam consagrado a aplicação e reconhecimento de um direito comercial supranacional.

18. "These rules are far more adapted to the circumstances than the lex mercatoria, which remains, both in scope and in practical significance, an elusive system and a mythical view of a transnational law of state contracts whose sources are elsewhere". Georges R. Delaume, Comparative analysis as a basis of law in state contracts: the myth of the lex mercatoria, in Tulane Law Review, v. 63, n. 3, Feb. 1989, p. 611. 
Nessa linha, sentença sempre lembrada é a do Tribunal de Grande Instância de Paris, adotada em 1981, que decidiu "à vista do caráter internacional do contrato, abandonar todas as referências que o vinculasssem a uma legislação específica, fosse turca ou francesa, e aplicar a lex mercatoria internacional". ${ }^{19}$

A Câmara de Comércio Internacional de Paris, através de suas regras de arbitragem, tem permitido ao árbitro julgar de conformidade com "les usages du commerce" e, ainda relativamente à arbitragem, o Código de Processo Civil francês, em seu artigo 1.496, admite que o árbitro tenha presente o costume comercial, como igualmente o fazem vários acordos e convenções internacionais.

A rigor, todas as referências convergem para o costume comercial internacional, referido como a grande base onde se estrutura a lex mercatoria moderna. Entretanto, o costume internacional não é "qualquer costume". Há de ser aceito e consagrado pelos direitos nacionais, conquanto não viole a ordem pública. Um costume comercial recusado por um ou mais direitos nacionais seria uma fonte de direito etérea, inacessível à realidade do próprio comércio, este sim adstrito a um ou mais territórios nacionais, vinculados a um ou mais Estados, que por sua vez se vinculam a um ou mais direitos positivos, frutos do poder jurisdicional soberano de cada um daqueles Estados.

Um costume comercial, para que seja considerado como fonte aceitável de direito, há de ser um costume reconhecido como não violador da ordem pública, representativo de uma tendência comercial legalmente aceitável, apto a ser acatado pelos tribunais. Um costume contra legem terá contra seu reconhecimento uma barreira praticamente intransponível.

No mesmo sentido, a Câmara de Comércio Internacional de Paris revela clara preocupação com a adequação do laudo arbitral por ela prolatado a direitos nacionais que com a matéria arbitrada eventualmente possam se vincular, deixando patente no art. 26 de suas Regras de Arbitragem que "o árbitro deve envidar esforços para assegurar que o laudo seja executável" Um laudo arbitral só será "executável" se não conflitar com o direito positivo ou a ordem pública do Estado onde se buscará a execução.

19. V. referência a tal decisāo na nota 12. 
7. Tentativas e dificuldades.

Ante as divergências na definição da lex mercatoria e a inconteste permanência dos direitos nacionais soberanos, algumas tentativas curiosas têm sido levadas a efeito, objetivando consagrar, ou ao menos disseminar, essa nova lei do comércio internacional.

Estranha simbiose entre direito nacional e lex mercatoria apátrida resultou de lei promulgada no Estado de Nova York, no ano de 1984, através da qual ficou consignado que quando um contrato envolva soma superior a US\$ $250,000.00$, ficam as partes autorizadas a adotar a lei de Nova York para reger tal contrato, ainda que o objeto do mesmo não guarde qualquer relação com aquele Estado norte-americano. A mesma lei preceitua que, se o valor do contrato for superior a um milhão de dólares (o que não é incomum nas relações financeiras e comerciais internacionais), além do direito de Nova York, podem as partes eleger o foro nova-iorquino, mesmo quando a relação contratual nenhuma vinculação tenha com aquele Estado. 20

Tal proposta revela a dificuldade do estabelecimento de uma lex mercatoria amplamente conhecida e reconhecida, abrindo a possibilidade de se buscar no direito positivo soberano de Nova York a estrutura para um direito transnacional. A dificuldade de se dar amplo conhecimento, ou mesmo um conteúdo inquestionável à lex mercatoria, fez com que o legislador nova-iorquino transformasse seu direito positivo estadual, conhecido e facilmente acessível a todos, em lex mercatoria, apta a ser escolhida para reger as mais importantes e valiosas relações comerciais internacionais.

Assim como a moeda norte-americana, o dólar, acabou por se transformar no padrão monetário internacional, a tentativa do legislador de Nova York parece ser a de transformar aquela legislação estadual em lei padrão para o comércio e finanças internacionais.

A extensão e diversificação do mercado mundial, onde a multiplicidade de costumes e culturas atingem diretamente as formas de fazer comércio, constituem-se em barreiras adicionais à uniformização e aceitação da

20. Act of July 19, 1984, ch. 421, 1984, N.Y. Laws 1406, N.Y. Gen. Oblig. Law, 5-1402, 5-1404 (McKinney Supp. 1988), cit. por Georges Delaume, ob. cit., nota 18, p. 581. 
lex mercatoria. A tarefa era inquestionavelmente mais simples na Idade Média, onde distâncias geográficas, culturais e costumeiras eram bastante menores.

Na defesa da disseminação do conceito da lex mercatoria, alguns chegam mesmo a sugerir que a superação de tais barreiras, existentes no mundo atual, somente seria viável a partir da formação de um núcleo constituído por um pequeno número de mercados privilegiados, sendo que os demais, se concordassem, iriam aderindo às regras formuladas pelo grupo do núcleo inicial. $^{21}$

Berthold Goldman, defensor pioneiro de uma lex mercatoria autônoma e independente, um verdadeiro direito supranacional, atenua essa posição quando, em trabalho apresentado em 1985, procura uma definição mais realista para o conceito, atento à realidade dos direitos nacionais. Partindo de sua definição de 1964, quando via na lex mercatoria um sistema ou ordem jurídica supranacional, desvinculada das ordens jurídicas nacionais, admite finalmente que a "lex mercatoria é um conjunto de princípios gerais e regras costumeiras, referidas espontaneamente ou criadas dentro da estrutura do comércio internacional, sem referência a um sistema jurídico nacional em particular". 22

Esta conceituação mais recente de Goldman, a ver na lex mercatoria apenas um conjunto de princípios e regras de costume (e não mais um sistema ou ordem jurídica supranacional), de certa forma, é antagônica à colocação defendida por Philippe Kahn e Fouchard, que ainda insistem em conceituá-la como um sistema de normas nascido da coesão de regras de caráter profissional ou associativo adotadas pelos comerciantes na ordem internacional. ${ }^{23}$

21. v. Christoph W.O. Stoecker, ob. cit., nota 13, p. 107.

22. Berthold Goldman, The applicable law: general principles of law - the lex mercatoria, in Contemporary problems in international arbitration, Julian D. M. Lew, Ed., p. 116.

23. "The parties to an international contract sometimes agree not to have their dispute governed by national law. Instead they submit it to the customs and usages of international trade, to the rules of law which are common to all or most of the States engaged in international trade or to those States which are connected with the dispute. Where such common rules are not ascerlainable, the arbitrator applies the rule or chooses the soluction which appears to him to be the most appropriate and equitable. In doing so he considers the laws of several legal systems. This judicial process, which is parly an application of legal rules and partly a selective and creative process, is here called 
Um direito supranacional do comércio deve pressupor um corpo social capaz de construir um sistema jurídico, e tal corpo seria a sociedade dos comerciantes; por outro lado, tal sistema há de ter autonomia, ostentar uma incontestável independência das normas dos direitos positivos estatais, ademais de ser autocontido, inclusive no tocante às sanções que vier a aplicar (e principalmente nelas), dispondo coercitivamente para suas decisões.

A sutil mudança na posição teórica de Goldman é claro indício de que a lex mercatoria não logrou atingir a condição de um direito transnacional, autônomo e positivado. Resta um trabalho muito grande e imensas conquistas devem ser feitas sobre as soberanias nacionais, para que se possa admitir um contrato regido apenas e tão-somente pela lex mercatoria. No atual estágio do comércio internacional, de preservação necessária das soberanias estatais, a admissão de um contrato regido por um direito transnacional merece as mesmas dúvidas e críticas que se faziam às frustradas tentativas de criação de um "contrato sem lei", durante as décadas de 60 e 70, que redundaram na inequívoca e praticamente unânime conclusão de que não se pode admitir um contrato no vácuo. ${ }^{24}$

A proposta de uma nova lex mercatoria tem inegavelmente um objetivo prático de valor considerável, buscando dar maior eficiência ao comércio internacional e, principalmente, solucionar com rapidez as pendências nele surgidas. Lex mercatoria e arbitragem comercial internacional são os remédios mais frequentemente buscados como solução para os grandes problemas surgidos no comércio internacional. O reconhecimento de que os direitos nacionais prevalecem no comércio entre nações, bem como a constatação de que a lex mercatoria ainda não alcançou os contornos de um direito supranacional autônomo e autocontido, não são suficientes para decretar o fracasso das tentativas de uniformização das regras jurídicas para o comércio extra-fronteiras. Quando se busca dar maior praticidade e eficiência ao comércio internacional, a posição maniqueísta de alguns autores não pode ser construtiva.

application of the lex mercatoria." $\mathrm{O}$. Lando, The lex mercatoria in international commercial arbitration, in The International and Comparative Law Quarterly, n. 34, 1985, p. 747.

24. Para uma análise das críticas ao "contrato sem lei", v. Hermes Marcelo Huck, ob. cit., nota 17, p. 49. 
Nada agrega ao progresso do direito do comércio internacional a insistência por uma lex mercatoria com contornos teóricos que a realidade não the atribui. 25

É difícil e constrangedora a situação em que um tribunal nacional recusa o reconhecimento e execução de uma sentença estrangeira (ou um laudo arbitral), passo final e muitas vezes inevitável de uma pendência surgida no comércio internacional, fundado em razões de ordem pública, frequentemente ditadas pela falta de fundamento da sentença estrangeira em determinado e específico direito nacional.

As decisões arbitrais, quando fundamentadas nos princípios supranacionais do comércio internacional, padecem desta mesma dificuldade. Decisões arbitrais estribadas na lex mercatoria, buscando apenas a uniformização redutora das normas comerciais, muitas vezes concedem pouca importância a conceitos essenciais como justiça e equidade. Não se pode aceitar como sendo objetivo um direito (e uma jurisdição como a arbitragem) orientado exclusivamente pelas frias regras mercantis, desatento às particularidades políticas e econômicas que o comércio internacional reflete, muito especialmente no tocante às desigualdades econômicas entre as nações, desigualdades essas que podem ser minimizadas com o uso adequado das práticas do comércio internacional.

25. Os teóricos maniqueístas ameaçam o comércio internacional com as "incertezas" dos direitos nacionais, caso o conceito de uma lex mercatoria não seja desde logo aceito e adotado. Para esses autores a alternativa da lex mercatoria é a incerteza e o cáos. José Alexandre Tavares Guerreiro descreve com clareza essa colocação, quando afirma que "essa verdadeira desnacionalização do contrato e da arbitragem é vista como fenômeno corrente no mundo contemporâneo, com significativa freqüência, e quase sempre suscitando a proposição dilemática: ou se adota essa normatividade supranacional, que ganha corpo com o título de lex mercatoria, pela razão que ela permite soluções que atendem à necessidade e conveniência das partes, com eficiência e neutralidade, mas com o risco, sempre presente, da incerteza ou da incalculabilidade quanto ao resultado final da decisāo arbitral, ou se permanece sob a égide dos mecanismos tradicionais das regras de conflito, com apelo necessário às legislaçōes nacionais, o que aparentemente tem a seu favor maior certeza do direito aplicável, mas que em muitas oportunidades, não tem conduzido as partes a soluções razoáveis e equitativas, como seria evidentemente de desejar". Ob. cit., nota 3, p. 226. 
8. Crítica da lex mercatoria.

Cumpre recordar que a arbitragem comercial internacional, consagrada como artífice maior da propagação da lex mercatoria, é, por sua própria natureza, falha nessa tarefa. $O$ progresso da uniformização e mesmo da consagração de um sistema desnacionalizado, autônomo e autocontido em busca de um direito do comércio internacional se choca com o sigilo $\mathrm{e}$ confidencialidade que, muita vez, cercam os laudos arbitrais, além do enfoque casuístico que os árbitros usualmente procuram imprimir na solução de pendências. Não é tarefa fácil falar-se em jurisprudência arbitral.

Uma visão crítica da lex mercatoria é compartilhada por Paul Lagarde, que não lhe admite a condição de ordem jurídica por lhe faltar organização suficiente e coesão social à sociedade dos comerciantes de onde se origina. Mesmo no campo da arbitragem comercial internacional, onde se têm permitido amplas concessões à aplicação de direito transnacional, entende Lagarde não ser admissível a aplicação pelos árbitros da lex mercatoria, salvo expressa autorização das partes. À falta dessa indicação pelas partes, deverão os árbitros recorrer a um direito nacional para a solução da pendência arbitrada. 26

Lagarde argumenta que, mesmo valendo-se da formulação institucionalista do Direito, proposta por Santi Romano, que exige tão-somente um grupo social organizado para que suas normas caracterizem uma ordem jurídica, não seria ela suficiente para a comprovação da existência de uma lex mercatoria. Não há uma única sociedade organizada de mercadores. Consequentemente, ao invés de um, ter-se-ia uma pluralidade de direitos mercatórios, advindos das diferentes áreas do comércio internacional. ${ }^{27}$

Phillipe Kahn, conceituado defensor da lex mercatoria, é forçado a reconhecer ser necessário que os operadores do mercado internacional constituam um meio suficientemente homogêneo, para que a solidariedade

26. Paul Lagarde, Approche critique de la lex mercatoria, in Études offertes a Berthold Goldman. Le droit des relations économiques internationales, p. 125.

27. "Bref, au milieu lequel se développe le commerce international est lui-même si étendu, si diversifié et si cloisoné qu'on vient a douter qu'il puisse servir de cadre à une communauté pourvu d'un minimum d'organisation, a l'instar des autres exemples d'ordres juridiques déjà rencontrés". Paul Lagarde, ob. cit., nota 26, p. 138. 
profissional se faça sentir e que fiquem claras as necessidades jurídicas coerentes e adequadas. 28

Igualmente, sem reconhecer a lex mercatoria como um sistema ou ordem jurídica, Kassis a entende como um "fundo comum aos direitos nacionais". As regras do comércio internacional encontram-se sempre vinculadas a um direito nacional. ${ }^{29}$ Paralelamente a essa vinculação, deve haver uma aceitação dos princípios desse conjunto de regras pelos próprios direitos nacionais pois, caso contrário, a ordem pública soberana de cada Estado há de barrar a aplicação direta ou indireta desse mesmo conjunto de princípios perante o referido direito nacional.

O costume internacional e a lex mercatoria como expressão desse costume - representa papel fundamental como fonte de direito. Esse costume, entretanto, deve ser positivado pela jurisprudência, tratados ou leis nacionais. A mera aceitação das partes em um contrato, ou a determinação dos árbitros em um laudo, não têm o poder de transformar um específico costume comercial, ainda que admitido em certas circunstâncias, em regra de direito. $\mathrm{O}$ costume necessita aspirar ao Direito e assim obter um reconhecimento internacional, para ser consagrado como fonte desse Direito. Não é qualquer costume, comercial ou não, que traz intrinsecamente seu valor jurídico. Um costume jurídico deve referir-se necessariamente a valores de Direito. ${ }^{30}$

Há uma crescente tendência entre os teóricos do Direito Internacional, certamente muito maior do que dentro da própria sociedade dos comerciantes internacionais, no sentido da admissão de um conjunto de normas, ou mesmo de um sistema jurídico supranacional, fruto da prática do comércio internacional. Não se pode confundir essa tendência, esse desejo manifesto num sem número de artigos e trabalhos doutrinários, com a efetiva existência desse sistema denominado lex mercatoria, sob pena de transformar o estudo do Direito

28. Ob. cit., nota 4, p. 173.

29. Antoine Kassis, Problèmes de base de l'arbitrage en droit comparé et en droit international, Paris, L.G.D.J., 1987, p. 578.

30. Miguel Reale, Lições preliminares de direito, $8^{a}$ ed., São Paulo, Saraiva, 1981, p. 158. 
Internacional do Comércio num exercício de vontades e desejos, afastado da realidade comercial, sua base fundamental.

Tavares Guerreiro, em seu estudo sobre arbitragens comerciais internacionais, já aqui citado, ao defender a existência da lex mercatoria, ao menos no mundo das arbitragens, lembra Bobbio, quando o jurista italiano distingue duas concepções de direito, em sentido amplo e em sentido restrito, recusando-se a entender como verdadeira uma e falsa outra, mas adotando a qualificação de concepção oportuna e inoportuna. Usando a lição de Bobbio, a concepção de direito da lex mercatoria é inoportuna, enquanto nela se pretenda ver um sistema jurídico supranacional, pois vem marcada por uma ideologia que almeja ver afastada qualquer intervenção dos direitos nacionais sobre as relações do comércio internacional. Pretender ignorar o papel desempenhado pelo Estado nas relações econômicas, financeiras e comerciais internacionais é, no mínimo, esconder a verdade. Sem qualquer defesa do intervencionismo, não se pode negar que o Estado deva exercer função essencial nas relações do comércio internacional, buscando minimizar as distorções que o flagrante desequilíbrio econômico entre as nações injeta nas relações comerciais.

Não há um direito vagando no espaço. Mesmo o costume depende do reconhecimento dos tribunais. São os tribunais estatais que consagram a produção espontânea de práticas em normas consuetudinárias. A constantemente lembrada decisão bissexta do tribunal francês que consagrou a lex mercatoria como fonte de direito, funciona como prova cabal de que mesmo a lex mercatoria aspira a ser consagrada e reconhecida por um tribunal nacional. Há uma submissão hierárquica entre o direito nacional (via tribunal) que consagra e a lex mercatoria que é por ele aceita. Sem descambar para o perigoso terreno das hipóteses (onde geralmente vivem os argumentos em favor dessa corrente), não parece haver dúvida, em caso de conflito entre a lex mercatoria e o direito nacional, sobre qual deles haveria de prevalecer perante um tribunal nacional, ainda que francês. A força obrigatória de um contrato provém exclusivamente do sistema legal que cria e garante a obrigação. ${ }^{31}$

31. A propósito do tema, cumpre lembrar a inaceitabilidade do contrato no vácuo, sem vínculos com qualquer direito nacional, cujo conceito foi repelido até em decisōes arbitrais memoráveis, como o Caso Aramco, quando o tribunal afirma que "il est certain qu'un contrat 
O conceito de uma lex mercatoria exerce imenso fascínio sobre o internacionalista. $O$ comércio internacional desvinculado das limitações impostas pelos direitos nacionais é um horizonte tentador. A privatizaçāo das regras desse comércio traria inegáveis vantagens de ordem prática. A partir dessa perspectiva, não há que se descuidar ou abandonar as hipóteses que orientam para a uniformização do direito do comércio internacional. Mas esse trabalho deve ser desenvolvido sem delírios ou fantasias. A reflexão sobre a lex mercatoria, sua origem, evolução e estágio,é particularmente adequada quando se tem presente o problema da execução de sentença estrangeira. É nesse campo que ficam patentes e visíveis as grandes barreiras impostas pelas soberanias nacionais.

Um contrato comercial internacional, envolvendo o trabalho e a riqueza das partes deve ser protegido contra um possível inadimplemento. A proteção necessariamente representa a possibilidade de uma execução judicial ou forçada. Um contrato regido por uma lex mercatoria não reconhecida restaria desprotegido dessa execução.

$O$ ideal da lex mercatoria deve ser alimentado dentro de um quadro de realismo, no qual os direitos e as soberanias nacionais ainda definem o tom. Há necessidade de se tratar essa aspiração com grande prudência, pois é inaceitável o acolhimento de um conceito de lex mercatoria tão abrangente que viria a englobar inteiramente o Direito do Comércio Internacional.

Sobra razão a Lagarde quando, mesmo reconhecendo os aspectos frágeis e pouco lógicos do conceito, ou da proposta que o conceito encerra, admite tratar-se a lex mercatoria "de um dos mais formidáveis desafios já apresentados ao Direito Internacional Privado" 32

Um comércio desvinculado das leis nacionais, antes de representar uma supressão de fronteiras, significa um comércio sem barreiras políticas. Os direitos nacionais impõem suas razões de ordem jurídica às relações comerciais internacionais. Um imenso mercado mundial, regulado apenas por regras autogeradas, certamente há de ignorar qualquer razão que não seja razão dẹ mercado. A adoção irrestrita de uma lex mercatoria representará a consagração

quelconque ne peut pas exister in vacuo, mais doit reposer sur un droit". Decisão publicada in Revue Critique de Droit International Privé, 1950, p. 609.

32. Ob. cit., nota 26, p. 149. 
absoluta da lei do mercado, despida de qualquer preocupação ou restrição de caráter jurídico nacional, ou principalmente político.

Nesse quadro, importam apenas objetivos econômicos e financeiros. A sociedade dos international merchants sai em busca de suas conveniências, da otimização de seus lucros, sem consideração por interesses nacionais, macroeconômicos, que devem ser protegidos por seus próprios direitos, mas quase sempre desconsiderados pelas sempre eficientes leis de mercado.

Os direitos nacionais, fruto das políticas econômicas e sociais (e por conseqüência jurídicas) de cada grupo nacional, representam uma barreira ao sofisticado conceito de eficiência pragmática, tão almejado entre os responsáveis pelo comércio internacional, quando importa apenas o resultado final obtido e insofismavelmente dimensionado pela regra do lucro.

A supressão total dos direitos nacionais, ou mesmo sua submissão a uma internacionalizada lex mercatoria, com a conseqüente eliminação das razões de ordem política e social, implicaria fatalmente o predomínio exclusivo das leis de mercado. A especulação, nessa hipótese, seria inevitável.

O comércio internacional, adstrito apenas a suas próprias conveniências e regras, desconsiderando as peculiaridades políticas e econômicas de cada grupo nacional, seu estágio de desenvolvimento, suas possibilidades e deficiências, é campo aberto para a especulação financeira internacional, onde os produtos nacionais serão apenas peças de um complexo tabuleiro, sujeitas exclusivamente à avaliação fria de resultados de balanço.

O mais flàgrante exemplo de um comércio desnacionalizado, sem limites nacionais, vinculado exclusivamente a suas próprias regras, foi o estágio buscado pelos grandes bancos na elaboração do modelo financeiro internacional denominado euro mercado. Esse mercado, criado, regulado e gerido pelos bancos, passou a ser uma terra de ninguém, onde não existiam controles e onde qualquer um podia operar ou simplesmente investir. Conseqüência direta desse modelo caótico foi o imenso endividamento dos países subdesenvolvidos, gerador da notável e ainda incontrolada crise internacional dos anos 80.33

33. "O euromercado transformou o caráter da atividade bancária. Ao unir mercados financeiros nacionais, ele criou um único mercado mundial de dinheiro, transnacional e virtualmente livre de 
Da perspectiva de um advogado americano acostumado à prática dos contratos internacionais, a lex mercatoria é, na realidade, um enigma criado por um paradoxo que vem colocando muitos investidores num dilema. $O$ paradoxo, por sua vez, criou um dilema do qual a única saída é chegar-se ao enigma, por meio de falácias. ${ }^{34}$

qualquer ação de governos. Como coloca o Business Week: 'No lugar de bancos locais transacionando numa única moeda, em um mercado nacional como a atividade bancária tradicionalmente fazia - existe agora um vasto e integrado sistema mundial de capitais e moedas, $o$ qual pode movimentar milhões de eurodólares, euromarcos e outras moedas 'sem pátria' 24 horas por dia, por todos os cantos do mundo. Grandes montantes dessas euromoedas transpuseram fronteiras nacionais e se livraram das mãos dos governos apesar dos crescentes e vigorosos controles cambiais com o intuito de diminuir o fluxo de capital de país para país. Por conseguinte, $o$ dinheiro se instalou nos euromercados, onde não existem controles e onde qualquer um pode operar ou apenas investir" Michael Moffit, $O$ dinheiro do mundo: de Bretton Woods à beira da insolvência, São Paulo, Paz e Terra, 1984, p. 65.

34. Keith Highet, The enigma of the lex mercatoria, in Tulane Law Review, v. 63, n. 3, Feb. 1989 , p. 615. 